\title{
KONTROL STRUKTUR GEOLOGI PADA KEMUNCULAN MATA AIR PANAS BUMI DAERAH SUBANG, JAWA BARAT
}

\author{
Sachrul Iswahyudi, Muhamad Afirudin Pamungkas, Huzaely Latief Sunan, dan Maulana Rizki Aditama \\ Departemen Teknik Geologi, Fakultas Teknik, Universitas Jenderal Soedirman \\ e-mail : sachrul.iswahyudi@unsoed.ac.id
}

\begin{abstract}
Abstrak. Mata air panas Ciniru dan Subang terletak dibagian tenggara Gunung Ciremai, tepatnya terletak di Desa Subang, Kecamatan Subang, Kabupaten Kuningan, Jawa Barat. Terdapat tiga manifestasi panas bumi berupa mata air panas di Daerah Subang, yaitu dua mata air panas di Daerah Ciniru dan satu mata air panas Daerah Subang. Mata air panas Ciniru 1 keluar dari litologi batulempung, terdapat beberapa keluaran pada satu lokasi yang saling berdekatan, memiliki sinter travertin, rasa asin dan warna air berwarna coklat. Mata air panas Ciniru 2 keluar dari rekahan batuan yang terdapat di bawah tebing dengan litologi batupasir. Sedangkan mata air panas Subang keluar dari rekahan batupasir. Penelitian ini menggunakan metode pemetaan geologi, analisis anomali gaya berat, dan geokimia air mata air panas. Ketiga mata air panas terletak pada suatu kelurusan struktur geologi yang berarah relatif utara-selatan. Kehadiran stuktur geologi mengontrol kemunculan mata air panas di daerah penelitian. Beberapa struktur yang ditemukan adalah sesar mendatar kiri, sesar naik, dan lipatan sinklin dan antiklin. Berdasarkan analisis anomali residual dan geologi menunjukan perbedaan anomali yang signifikan yang kemudian diinterpretasikan sebagai daerah dengan litologi kompak batuan beku dengan densitas 2.8 $3.1 \mathrm{gr} / \mathrm{cm}^{3}$; dan zona permeabel struktur geologi dengan densitas $1.97-2.6 \mathrm{gr} / \mathrm{cm}^{3}$. Ketiga manifestasi masuk dalam tipe air klorida, memiliki satu reservoir yang sama, memiliki temperatur dari $136^{\circ} \mathrm{C}-159^{\circ} \mathrm{C}$, dan tergolong sebagai sistem panas bumi temperatur sedang.

Kata Kunci: Subang; Ciniru; anomali gaya berat; geokimia air panas
\end{abstract}

\begin{abstract}
Ciniru and Subang hot springs are located in the southeastern part of Mount Ciremai, precisely located in the Subang Village, Subang District, Kuningan District, West Java. There are three manifestations of geothermal in the form of hot springs in the Subang Region. It is two hot springs in the Ciniru Region and one hot spring in the Subang Region. Ciniru 1 hot springs come out of claystone lithology, there are several outputs in one location that are close to each other, they have sinter tervertine, have a salty taste and the color of the water is brown. Ciniru 2 hot springs emerge from rock fractures found beneath cliffs with sandstone lithology. While the Subang hot springs come from fractures in sandstone. This study uses geological mapping, gravity anomaly analysis, and geochemical water analyses methods. The three hot springs are located in an alignment of the north-south direction of the geological structure. The presence of a geological structure controls the appearance of hot springs in the study area. Some of the geological structures were left strike slip and reverse faults, and syncline and anticline folds. Based on the analysis of residual and geological anomalies, it shows a significant anomaly difference which is then interpreted as an area with compact lithology of igneous rock with a density of 2.8 - $3.1 \mathrm{gr} / \mathrm{cm}^{3}$; and permeable zones of geological structures with densities of $1.97-2.6 \mathrm{gr} / \mathrm{cm}^{3}$. The three manifestations were the chloride water type, have one system or reservoir, have temperatures of $136^{\circ}-159^{\circ} \mathrm{C}$, enter the medium temperature geothermal system.
\end{abstract}

Keywords: Subang; Ciniru; gravity anomaly; geochemical hot water

\section{PENDAHULUAN}

Indonesia dilalui oleh jalur gunungapi atau sebagai Ring of Fire yang melalui Pulau Sumatra, Pulau Jawa, Kepulauan Nusa Tenggara, Pulau Sulawesi, dan Kepulauan Maluku. Jalur gunungapi ini sebagian besar berpotensi menghasilkan energi panas bumi yang besar (Widarto dkk., 2003;
Pratomo, 2006). Syarat pembentukan sistem panas bumi tersusun atas tiga faktor yaitu adanya sumber panas (heat source), batuan waduk (reservoir), dan batuan penudung (seal). Air panas dan ataupun uap air akan naik ke permukaan disebabkan adanya arus konveksi melalui rekahan atau zona lemah pada batuan sehingga muncul ke permukaan sebagai 
manifestasi panas bumi. Zona lemah pada batuan dapat disebabkan oleh struktur geologi yang membentuk zona hancuran, sesar, dan rekahan pada batuan sehingga menjadi jalur fluida panas bumi untuk naik ke permukaan. Keluarnya fluida panas bumi dapat menyebabkan batuan samping yang dilewati terubahkan (alterasi). Batuan yang telah terubah dapat menjadi batuan penudung (seal). Lapangan panas bumi dapat terjadi terutama di lingkungan busur volkanik atau magmatik yang dibawahnya terdapat ruang-ruang magma yang berperan sebagai sumber panas (Herman, 2009). Potensi panas bumi yang terdapat di Pulau Jawa terjadi karena hasil gerakan konvergen antara Lempeng Indo-Australia di sebelah selatan Pulau Jawa dan Lempeng Eurasia di sebelah utara Pulau Jawa.

Mata air panas Subang telah memberikan manfaat kepada masyarakat Desa Subang sebagai penggerak ekonomi dengan memanfaatkan mata air panas sebagai destinasi wisata pemandian air panas. Destinasi wisata pemandian air panas dapat berjalan lama karena mata air panas memiliki umur yang panjang tergantung pada besar batuan waduk (reservoir) dan sumber panas (heat source).

Tujuan penelitian ini adalah mengidentifikasi sistem panasbumi dan faktor-faktor yang mengontrol kemunculan beberapa mata air panas di Daerah Subang, Kecamatan Subang, Kabupaten Kuningan, Jawa Barat. Pendekatan yang digunakan dalam penelitian ini adalah analisis-analisis gaya berat, geokimia fluida dan geologi.

\section{Penelitian Terdahulu}

Beberapa penelitian geologi pada daerah Subang dan sekitarnya, Kecamatan Subang, Kabupaten Kuningan, Provinsi Jawa Barat telah dilakukan oleh para peneliti terdahulu, baik berupa penelitian geologi, geokimia, maupun geofisika. Para peneliti tersebut antara lain:

a. Faizal Muhamadsyah, Edy Sunardi, Vijaya Isnaniawardhani (2012) dengan judul Karakteristik Geologi Daerah Gunungan Lumpur Ciuyah. b. Ajiprabhawa Sukmajaya (2013) dengan judul Biostratigrafi Endapan Turbidit Miosen di Daerah Ciniru, Kabupaten Ciniru.

c. Radinal J. Bahri, Mimin Iryanti, dan Dadan Dani Wardhana (2015) dengan judul Aplikasi Metode Gaya berat untuk Memprediksi Prospek Panas Bumi di Daerah Kuningan, Jawa Barat.

d. Bella Agung Pratama (2016) dengan judul Geologi dan Geokimia Air Panas Bumi Daerah Cipakem, Kecamatan Ciniru, Kabupaten Kuningan, Jawa Barat.

\section{METODE PENELITIAN}

Metode yang digunakan untuk mengetahui kontrol struktur geologi pada kemunculan mata air panas bumi Daerah Subang yaitu pemetaan geologi untuk mengetahui tatanan stratigrafi dan struktur geologi di lokasi penelitian, analisis anomali gaya berat untuk mengetahui anomali pada daerah penelitian, serta analisis geokimia mata air panas.

\section{HASIL DAN PEMBAHASAN}

Stratigrafi daerah penelitian terdiri dari lima satuan, satuan dari tua ke muda yaitu: satuan batulempung, satuan batupasir Bangunjaya, satuan batupasir Gununghurip, intrusi andesit, dan breksi laharik. Satuan batulempung tersusun atas batulempung kabonatan dengan warna abu-abu kehitaman, batupasir karbonatan, dan setempat terdapat kalkarenit. Satuan batupasir Bangunjaya tersusun atas batupasir berfragmen terumbu pada bagian bawah, batupasir karbonatan, setempat terdapat kalkarenit, dan dibagian atas terdapat tuf. Satuan batupasir Gununghurip pada bagian bawah tersusun atas litologi breksi andesit, di atas tersusun batupasir karbonatan dan terdapat tuf, satuan ini diendapkan secara menjemari dengan satuan batupasir Bagunjaya. Intrusi andesit berupa sill yang memanjang dari barat-timur memotong satuan batulempung dan dike yang memotong satuan batupasir Gununghurip. Breksi laharik diendapkan secara tidak selaras diatas satuan batupasir Gununghurip berupa ketidakselarasan angular unconformity. 
Struktur geologi daerah penelitian terdiri dari sesar naik Cipedes berarah relatif barat-timur yang terpotong oleh sesar mendatar kiri Maleber yang berarah relatif timur laut-barat daya, sesar naik Cilogawa berarah relatif barat-timur, di selatan sesar naik Cilogawa tedapat sesar naik Rangawangsa berarah barat-timur, sesar naik Argasari terletak di selatan lokasi penelitian berarah barat-timur, dan sesar mendatar kiri Paumahan berarah relatif utara-selatan. Terdapat lima antikilin dan tiga sinklin dari utara hingga selatan lokasi penelitian (Gambar 1).

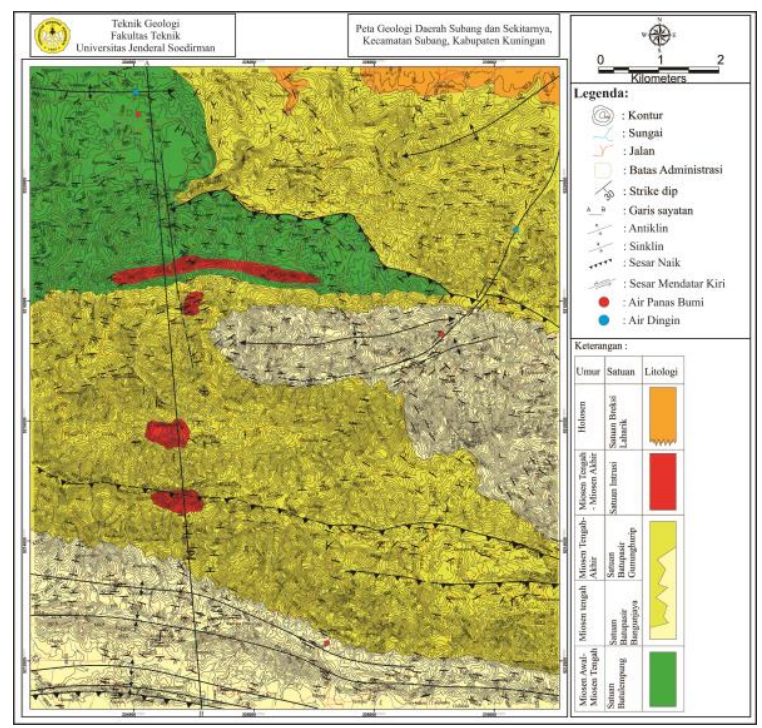

Gambar 1. Peta Geologi Daerah Subang

Anomali gaya berat mengunakan data airborne dan dilakukan analisis untuk mengetahui anomali residual dengan memisahkan anomali bouguer terhadap anomali regional. Anomali residual digunakan untuk interpretasi lebih lanjut karena anomali residual menggambarkan anomali dangkal pada lokasi penelitian. Anomali residual menunjukan bahwa anomali tinggi terdapat di utara dan selatan yang membentang dari barat ke timur dengan nilai anomali 4.0 - $20.8 \mathrm{mGal}$ dan anomali dengan nilai rendah terdapat pada tengah lokasi penelitian yang membentang dari barat ke timur dengan nilai anomali -11.3 hingga -25.2 mGal. Arah anomali relatif berarah barat-timur yang memiliki kesamaan dengan kelurusan yang terdapat di Daerah Subang (Gambar 2).

Anomali residual kemudian di inversi untuk mengetahui densitas dan gambaran penampang 2

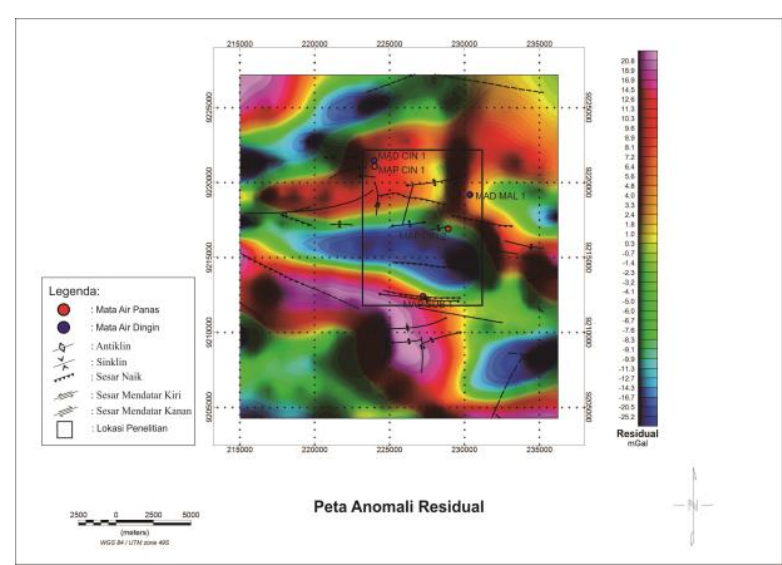

Gambar 2. Peta Anomali Residual Daerah Subang dan Sekitarnya

dimensi anomali residual. Hasil inversi menunjukkan nilai densitas dari $1.97-3.07 \mathrm{gr} / \mathrm{cm}^{3}$, nilai densitas tinggi dengan nilai $2.8-3.07 \mathrm{gr} / \mathrm{cm} 3$ diinterpretasikan sebagian batuan yang kompak yaitu sebagai batuan beku yang dapat berperan sebagai heat source diperkuat dengan data pemetaan langsung berupa intrusi yang tersingkap dipermukaan. Densitas rendah dengan nilai 1.97 $2.6 \mathrm{gr} / \mathrm{cm}^{3}$ sebagai batuan yang memiliki porositas dan permeabilitas yang tinggi diduga sebagai batuan waduk (reservoir) didukung dengan data pemetaan geologi secara langsung yaitu berupa satuan batupasir Bangunjaya dan batupasir Gununghurip (Gambar 3).

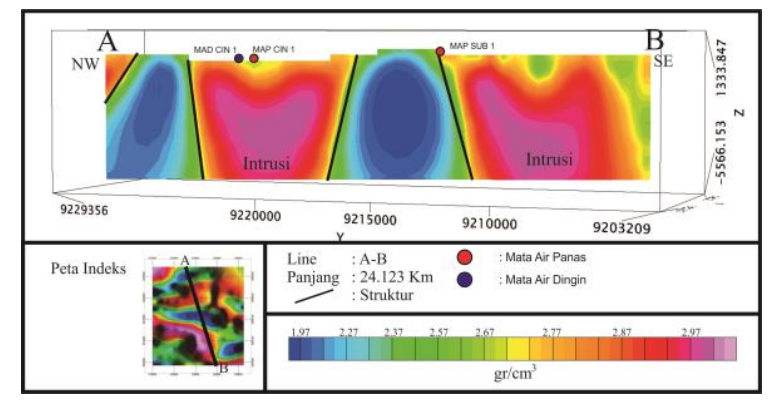

Gambar 3. Penampang Sayatan A-B Anomali Residual Daerah Subang dan Sekitarnya

Untuk mengetahui persebaran batuan yang diduga sebagai batuan waduk (reservoir) dan intrusi sebagai sumber panas dilakukan analisis 3 dimensi menggunakan aplikasi Oasis Montaj. Dari analisis tersebut didapatkan hasil bahwa kemungkinan batuan yang dapat berfungsi sebagai batuan waduk memiliki densitas antara $1.97-2.6 \mathrm{gr} / \mathrm{cm}^{3}$ yang membentang dari barat ke timur. Arah tersebut 
memiliki kesamaan dengan persebaran batuan yang terdapat pada daerah subang dengan arah barat timur. Kemudian dilakukan kompilasi antara data gaya berat dengan data geologi bahwa batuan yang diduga sebagai reservoir merupakan batupasir Bangunjaya dan batupasir Gununghurip (Gambar 4).

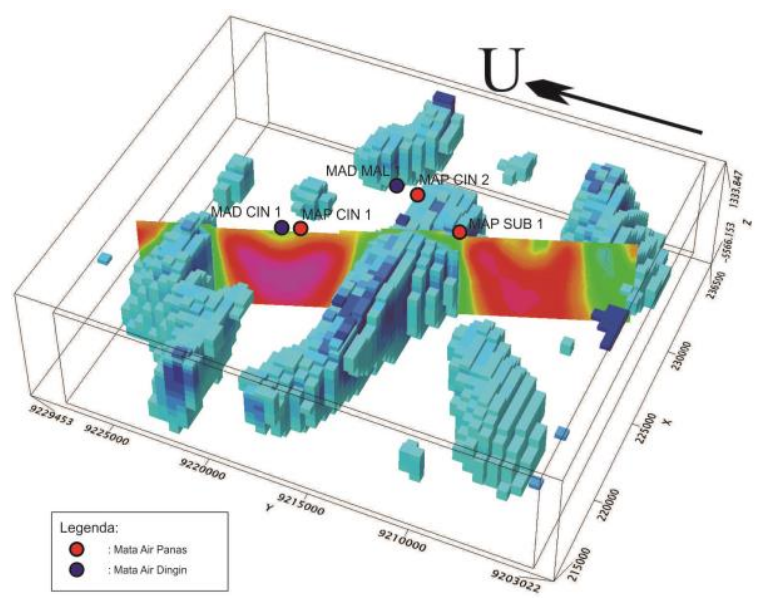

Gambar 4. Persebaran Batuan Waduk Daerah Subang dan sekitarnya

Batuan yang diduga sebagai sumber panas (intrusi) memiliki densitas berkisar antara $2.8-3.07 \mathrm{gr} / \mathrm{cm}^{2}$ yang membentang dari barat - timur yang memiliki kesamaan dengan arah sill dan kelurusan yang terdapat di lokasi penelitian, batuan sumber panas ini didukung dengan data pemetaan secara langsung yang berupa intrusi yaitu sill dan dike di lokasi penelitian (Gambar 5) .

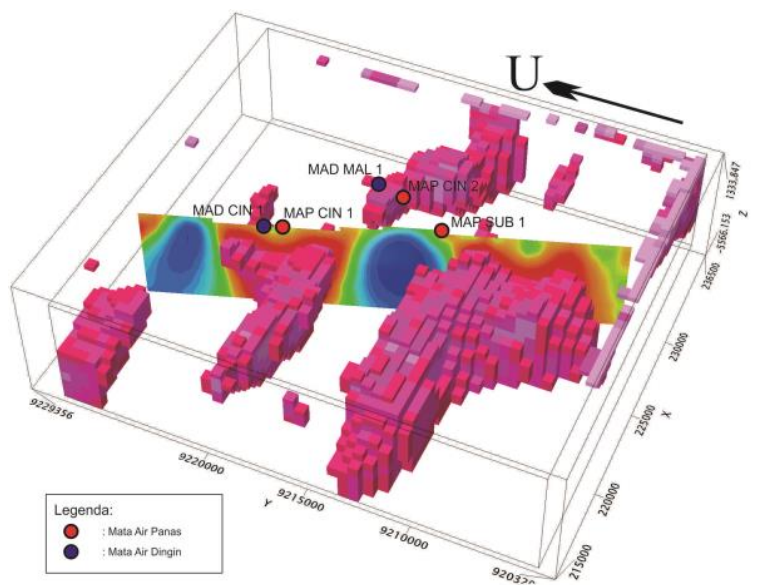

Gambar 5. Persebaran Batuan Sumber Panas Daerah Subang dan sekitarnya

Data hasil analisis geokimia (Tabel 1) digunakan untuk mengetahui tipe air, geoindikator, geotermometer, tipe air dingin, dan isotop air panas bumi. Berdasarkan hasil pengeplotan menggunakan diagram segitiga $\mathrm{Cl}-\mathrm{SO}_{4}-\mathrm{HCO}_{3}$, tiga manifestasi panas bumi menunjukkan satu jenis tipe air yaitu tipe air klorida. Tipe air ini mirip dengan air reservoir atau berasal dari air reservoir dalam. Air panas Ciniru 1 memiliki kandungan $\mathrm{Cl}$ yang sangat tinggi dan memiliki rasa asin dan berwarna coklat yang kemudian diinterpretasikan telah terkontaminasi dengan air formasi dari Formasi Pemali yang terbentuk pada lingkungan marine (Gambar 6).

\begin{tabular}{|c|c|c|c|c|c}
\hline Nama sampel & MAP SUB 1 & MAP CIN 1 & MAP CIN 2 & MAD CIN 1 & MAD MAL 1 \\
\hline Tanggal & $26 / 07 / 19$ & $27 / 07 / 19$ & $27 / 07 / 19$ & $30 / 07 / 19$ & $30 / 07 / 19$ \\
\hline Label sampel & MAP SUB 1 & MAP CIN 1 & MAP CIN 2 & MAD CIN 1 & MAD MAL 1 \\
\hline UTM timur & 227269 & 223978 & 228897 & 224047 & 230336 \\
\hline UTM utara & 9212428 & 9221112 & 9216956 & 9221487 & 9219205 \\
\hline Elevasi & 373 & 256 & 279 & 270 & 185 \\
\hline Suhu C & 63.6 & 31.6 & 43.1 & 28.2 & 28 \\
\hline pH & 7.69 & 7.82 & 8.42 & 8.37 & 8.43 \\
\hline Li & 0.01 & 25.22 & 0.01 & 0.01 & 0.01 \\
\hline Na & 129.38 & 13026.75 & 84.71 & 23.78 & 17.52 \\
\hline $\mathbf{K}$ & 2.90 & 444.19 & 2.38 & 2.47 & 2.60 \\
\hline $\mathbf{C a}$ & 16.88 & 101.24 & 42.34 & 97.08 & 116.78 \\
\hline $\mathbf{M g}$ & 1.22 & 335.55 & 5.16 & 13.88 & 7.75 \\
\hline SiO2 & 53.48 & 174.27 & 30.71 & 29.05 & 35 \\
\hline $\mathbf{B}$ & 2.25 & 265.53 & 2.45 & 0.20 & 0 \\
\hline $\mathbf{C l}$ & 213.00 & 20178.20 & 173.95 & 30.00 & \\
\hline $\mathbf{F}$ & 0.40 & & 0.64 & & \\
\hline SO4 & 10.00 & 126.89 & 20.00 & 30.00 & 20 \\
\hline $\mathbf{H C O 3}$ & 42.06 & 2939.27 & 84.87 & 264.81 & 279.24 \\
\hline CO3 & & & 12.73 & 44.06 & 53.86 \\
\hline NH4 & 1.19 & 7.53 & 1.00 & 0.82 & 0.5 \\
\hline As & & 0.20 & & 0.02 & 0.02 \\
\hline Fe & 0.00 & 0.85 & 0.02 & 0.12 & \\
\hline del 18 & -6.48 & 5.80 & -6.49 & -6.05 & -6.82 \\
\hline del D & -37.27 & -4.97 & -37.20 & -35.61 & -40.8 \\
\hline sum kation & 6.71 & 614.76 & 6.34 & 7.13 & 7.32 \\
\hline sum anion & 6.93 & 620.04 & 7.17 & 7.28 & 6.79 \\
\hline lon Balance & $-1.6 \%$ & $-0.4 \%$ & $-6.1 \%$ & $-1.0 \%$ & $3.8 \%$ \\
\hline & & & & & \\
\hline
\end{tabular}

Tabel 1. Data geokimia lokasi penelitian.

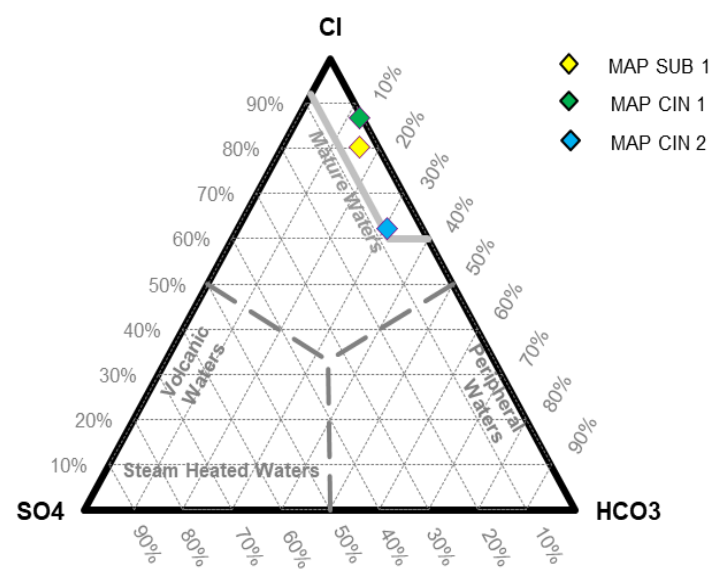

Gambar 6. Tipe air panas daerah Subang. 
Untuk mengetahui apakah air panasbumi berasal dari sistem atau reservoir yanga sama, digunakan unsur konservatif $\mathrm{Cl}, \mathrm{Li}$, dan $\mathrm{B}$. Berdasarkan hasil plotting menggunakan diagram segitiga $\mathrm{Cl}$, Li, dan $\mathrm{B}$ ketiga manifestasi panasbumi berada dalam kelompok yang sama, dan diinterpretasikan ketiga mata air panasbumi berasal dari sistem atau reservoir yang sama (Gambar 7).

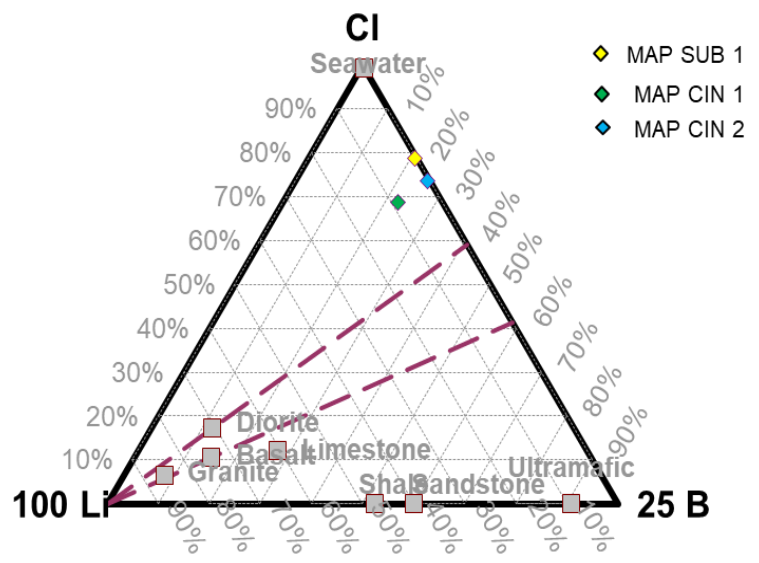

Gambar 7. Geoindikator pada daerah Subang.

Perkiraan temperatur reservoir menggunakan metode grafis dan persamaan. Metode grafis menggunakan diagram $\mathrm{Na}, \mathrm{K}$, dan $\mathrm{Mg}$ menghasilkan satu mata air panas yaitu MAP Ciniru 1 masuk kedalam zona partial equilibrium dan menunjukkan suhu $160^{\circ} \mathrm{C}$ dan 2 mata air panas masuk dalam zona immature water (Gambar 8). Menggunakan metode persamaan didapatkan hasil temperatur MAP Subang $136^{\circ} \mathrm{C}$, MAP Ciniru $1159^{\circ} \mathrm{C}$, dan MAP Ciniru 2 dengan temperatur $148^{\circ} \mathrm{C}$ (Gambar 9).

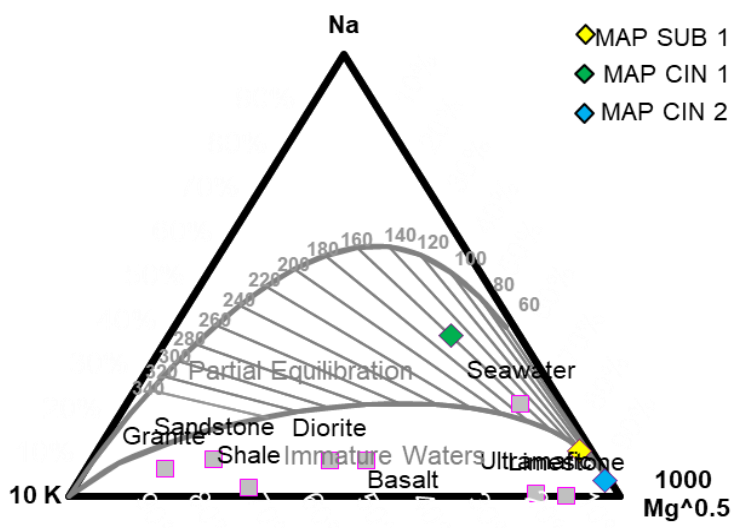

Gambar 8. Diagram geotermometer pada daerah Subang.
- Perhitungan Geotermometer Na/K (Giggenbach, 1988) MAP SUB1 $t^{\circ} \mathrm{C}=\frac{1390}{1.75-\log \left(\frac{\operatorname{Na}}{K}\right)}-273=\frac{1390}{1.75-\log \left(\frac{129.38}{2.90}\right)}-273=136^{\circ} \mathrm{C}$

- Perhitungan Geotermometer Na/K (Giggenbach, 1988) MAP CIN1 $t^{2} \mathrm{C}=\frac{1390}{1.75-\log \left(\frac{N a}{K}\right)}-273=\frac{1390}{1.75-\log \left(\frac{13026.75}{444.19}\right)}-273=159^{\circ} \mathrm{C}$

- Perhitungan Geotermometer Na/K (Giggenbach, 1988) MAP CIN2 $\mathrm{t}^{2} \mathrm{C}=\frac{1390}{1.75-\log \left(\frac{\mathrm{Na}}{K}\right)}-273=\frac{1390}{1.75-\log \left(\frac{84.71}{2.38}\right)}-273=148^{\circ} \mathrm{C}$

Gambar 9. Persamaan geotermometer pada daerah Subang.

Dari analisis 2 mata air dingin yaitu MAD Ciniru dan MAD Maleber pada diagram piper diinterpretasikan bahwa tipe air dingin berada pada tipe Magnesium Bicarbonate, tipe air ini merupakan tipe dengan kesadahan sementara dan dapat hilang jika dipanaskan, Magnesium Bicarbonate merupakan fresh ground water atau air dengan kandungan alkali tanah yang tinggi. Tipe air ini mengindikasikan bahwa air permukaan tidak terpengaruh oleh fluida panas bumi (Gambar 10).

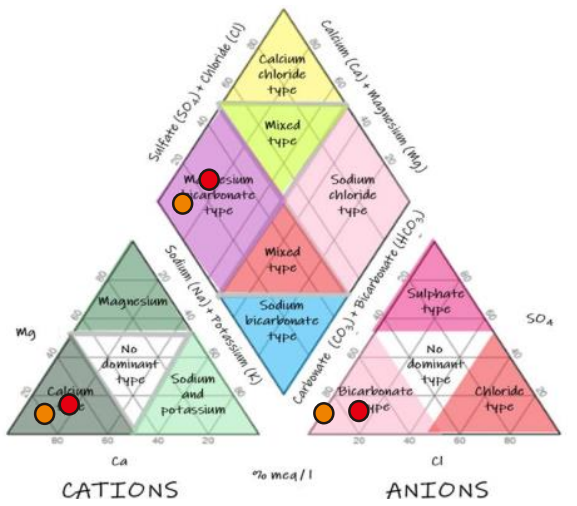

Gambar 10. Diagram piper pada daerah Subang.

Untuk mengetahui asal fluida panasbumi dilakukan analisis isotop keempat sampel air, yaitu 2 mata air panas (MAP Subang 1, MAP Ciniru 2) dan 2 mata air dingin (MAD Ciniru 1, dan MAD Maleber). Hasil analisis menunjukkan MAP Subang 1 dan MAP Ciniru 2 hampir berhimpit dengan garis air meteorik, yang diinterpretasikan kedua air mata air panas tersebut berasal dari air meteorik. Sedangkan plotting MAP Ciniru 1 mendekati daerah magmatik, yang diinterpretasikan air MAP Ciniru 1 berasal dari air magmatik (Gambar 11). Air panas MAP Ciniru 1 juga diinterpretasikan merupakan campuran air formasi (Gambar 6). 


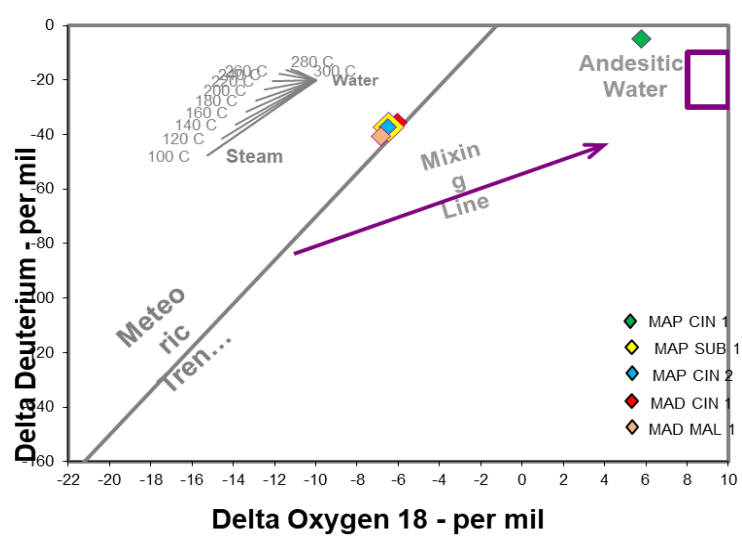

Gambar 11. Diagram geotermometer pada daerah Subang.

\section{PENUTUP}

\section{Simpulan}

Simpulan berdasarkan penelitian yang dilakukan didapatkan bahwa terdapat 3 mata air panas Daerah Subang dengan tipe air klorida, berasal dari satu reservoir, memiliki temperatur reservoir $160^{\circ} \mathrm{C}$. Sistem panasbumi termasuk dalam sistem temperatur sedang. Mata air dingin tidak terkontaminasi dengan fluida panas bumi. Semua mata air panas berasal dari air meteorik kecuali MAP Ciniru 1. Ketiga mata air panas keluar disebabkan karena rekahan/zona lemah yang diakibatkan oleh struktur geologi yang bekerja di lokasi penelitian.

\section{Ucapan Terima Kasih}

Terima kasih kami ucapkan kepada LPPM Universitas Jenderal Soedirman, rekan-rekan di Teknik Geologi UNSOED dan pihak-pihak yang telah membantu dalam publikasi tulisan ini.

\section{DAFTAR PUSTAKA}

Bahri, R.J., Iryanti, M. dan Wardhana, D.D. (2015), "APLIKASI METODE GAYABERAT UNTUK MEMPREDIKSI PROSPEK PANASBUMI DI DAERAH KUNINGAN, JAWA BARAT", Fibusi (Jurnal Online Fisika), Vol.3, No.3. Diambil dari http://journal.fpmipa.upi.edu/index.php/JOF/article/ view/546.

Muhamadsyah, F., Sunardi, E. dan Isnaniawardhani, V. (2012), "KARAKTERISTIK GEOLOGI DAERAH GUNUNGAN LUMPUR CIUYAH", Bulletin of Scientific
Contribution: GEOLOGY, Vol.10, No.2. http://doi.org/10.24198/bsc geology.v10i2.8278.

Giggenbach, W.F. (1988), "Geothermal dolute equilibria. derivation of Na-K-Mg-Ca geoindicators", Geochimica et Cosmochimica Acta, Vol.52, No.12, hal. 2749-2765. http://doi.org/10.1016/0016-7037(88)90143-3

Hochstein, M.P., Yang, Z. dan Etara, S. (1990), "The Fuzhou geothermal system (P.R.China): modelling study of a low temperature fracture zone system", Geothermics, Vol.19 No.1, hal. 43-60. http:// 10.1016/0375-6505(90)90065-J

Pratama, B.A. (2016), Geologi dan Geokimia Air Panas Bumi di Daerah Cipakem, Kecamatan Ciniru, Kabupaten Kuningan, Jawa Barat, Skripsi, Universitas Jenderal Soedirman, Purwokerto.

Sukmajaya, A. (2013), Geologi Daerah Ciniru dan Sekitarnya, Kecamatan Ciniru, Kabupaten Kuningan, Jawa Barat, Institut Teknologi Bandung, Bandung.

Widarto, D.S., Indarto, S. dan Gaffar, E.Z. (2003), "Hasil Awal Geotermometri Kimia Air Panas Lapangan Panasbumi Gedongsongo di Lereng Selatan Gunung Ungaran, Jawa Tengah", Buletin Geologi, Institut Teknologi Bandung, Bandung. 